www.revistadyo.com

\title{
Secuenciación con Almacenes Limitados. Una Revisión de la Literatura
}

Carlos Andrés, Julien Maheut.

Recibido: 23 de Febrero de 2018 / Aceptado: 13 de Junio de 2018

\section{Resumen}

Tradicionalmente, en la aproximación formal a la secuenciación de producción denominada en inglés Theory of Scheduling (o simplemente scheduling), se suele obviar la limitación de capacidad entre los diferentes recursos de cara a establecer el programa de producción. Sin embargo, el paradigma Lean Manufacturing ha dejado patente que la limitación de capacidad física en los sistemas productivos es una característica que influye en los resultados de los programas de producción, por lo que las configuraciones empezando a ser objeto de estudio en la dirección de operaciones. En este artículo se hace una revisión de las principales características de la secuenciación con almacenes limitados que se han abordado bajo la teoría de secuenciación y se resumen las referencias más importantes publicadas durante los últimos años. Finalmente, se presentan una serie de conclusiones con el objetivo de clarificar algunas líneas de interés para los investigadores del tema.

\section{Palabras clave}

Programación de la producción, secuenciación, capacidad limitada, almacén limitado, secuenciación con bloqueo, secuenciación sin esperas.

\section{Introducción}

Desde el artículo seminal de Johnson (1954), que marca el inicio tradicionalmente aceptado del interés científico por los problemas de programación de la producción en la dirección de operaciones, el número de publicaciones relacionadas con la teoría de secuenciación ha crecido de manera abrumadora, según se desprende de la Figura 1 obtenida a partir de las citas del Google Scholar consultadas en Febrero de 2018.

Figura 1 Evolución del número de citas de "scheduling” según el Google Scholar

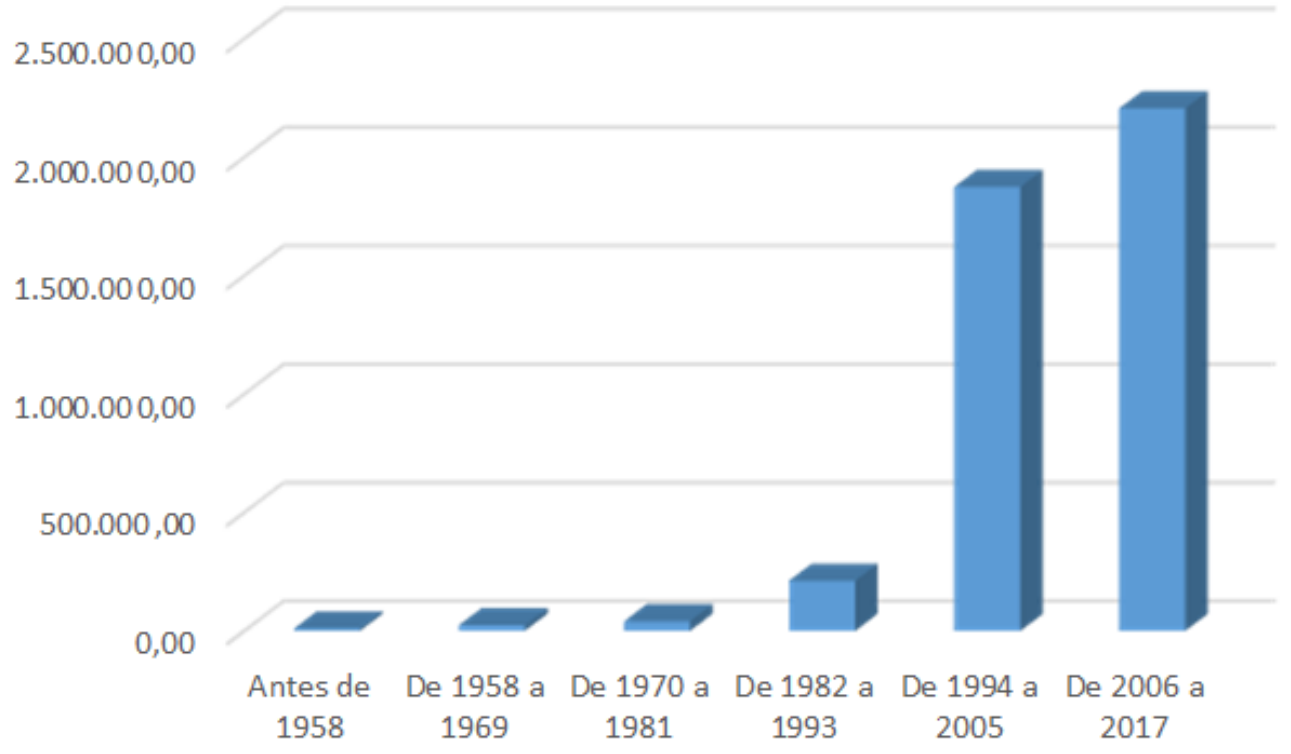


En la mayoría de la investigación realizadas en este campo se asume que existe una capacidad de almacenamiento infinito entre las máquinas del taller. Sin embargo, en los sistemas productivos reales siempre hay una limitación de capacidad debido a la necesidad física de que los trabajos esperen antes de ser procesados en una máquina, si ésta se encuentra ocupada procesando el trabajo previo de la secuencia. Esta limitación es más relevante cuanto mayor es el volumen o tamaño de las piezas o lotes procesados entre las máquinas.

Dado el interés, cada vez mayor, en abordar problemas de secuenciación con características realistas y la ausencia de una revisión bibliográfica sobre este aspecto, creemos necesario presentar este artículo con el objetivo de plantear una visión general sobre el tema y ayudar a los investigadores que desean desarrollar su trabajo en el área. Así, en el segundo apartado, se repasa la formalización más comúnmente usada en la teoría de secuenciación para expresar las limitaciones de capacidad, señalando algunas posibles carencias que creemos merecen ser estudiadas. A continuación, y como parte principal de este artículo se repasa la literatura existente al respecto para señalar aquellas áreas de interés que creemos que pueden ser objeto de estudio por parte de los investigadores en esta área. Finalmente, se establecen una serie de conclusiones que pueden ayudar a clarificar posibles trabajos futuros a los interesados en las líneas de trabajo en secuenciación con almacenes limitados.

\section{El problema de secuenciación con al- macenes limitados}

De acuerdo con Companys y Corominas (1996), un problema de Programación de la producción se define mediante la asignación, la secuenciación y la temporización de las operaciones necesarias para realizar un conjunto de $\mathrm{N}$ trabajos en $\mathrm{M}$ máquinas. A partir de esta definición, y en lo que resta del artículo, solamente se van a abordar aquellas referencias que han abordado la determinación de la secuencia de los trabajos, y los instantes de inicio y fin de las operaciones de los mismos en cada máquina, quedando fuera de nuestro análisis todos los métodos de asignación a capacidad finita que se estudian en la literatura relacionada con la planificación maestra a capacidad finita, la planificación de recursos de capacidad o capacity requirements planning (C.R.P.) o la visión basada en la tecnología de producción optimizada u optimized production technology (O.P.T.).
En primer lugar, se define un problema de secuenciación sin capacidad limitada como la ordenación y temporización de un conjunto de $\mathrm{N}$ trabajos $(\mathrm{i}=1, \ldots, \mathrm{N})$ en un conjunto de M máquinas, $(\mathrm{j}=1, . ., \mathrm{M})$, donde cada trabajo i consta de $\mathrm{Hi}$ operaciones $(\mathrm{h}=1, . ., \mathrm{Hi})$. Cada operación se realiza en una máquina de tal manera que para cada trabajo la operación $h$ se hace en una máquina diferente a la operación $h+1$. Además, el tiempo de proceso de la h-ésima operación del trabajo i en la máquina j se denota como $\mathrm{p}_{\mathrm{h}, \mathrm{i}, \mathrm{j}} \mathrm{y}$ tiene una duración finita y determinista, por lo que, para cada trabajo i, la operación $\mathrm{h}+1$ no puede empezar si no se ha terminado la operación h. También se asume que cada máquina solo puede realizar una operación a la vez y cada trabajo solo puede recibir una única operación simultáneamente. Esta secuenciación y temporización debe respetar las relaciones de precedencia existentes entre las diferentes operaciones de un mismo trabajo y minimizar una o varias medidas de eficiencia que, en la mayoría de las veces, tienen relación con las fechas de finalización de cada operación en cada una de las máquinas.

En los problemas de secuenciación sin capacidad limitada se asume que existe suficiente espacio de almacenamiento entre dos máquinas para almacenar los trabajos una vez han acabado en la primera de ellas. Sin embargo, en la realidad este espacio suele estar limitado. Esto quiere decir que, cuando se ha llenado el almacén intermedio, no se puede enviar el siguiente trabajo que finaliza en cualquiera de las máquinas que lo abastecen por lo que se produce un bloqueo en la máquina correspondiente hasta que alguno de los trabajos, que están en el almacén, es enviado a su siguiente operación (esto es, cuando la máquina a donde va ir el trabajo queda libre para poder procesar el trabajo). Como se comentará en la sección 3 de este artículo, en la mayoría de artículos analizados en la literatura, esta limitación se establece en base al número máximo de trabajos que pueden almacenarse en cada instante en los almacenes (asumiendo de esta manera que todos los trabajos tienen un volumen parecido o se transportan en contenedores estandarizados) sin entrar a formalizar las limitaciones de capacidad debidas al volumen físico u otra característica diferencial entre los trabajos secuenciados.

Para visualizar el problema descrito, supongamos un taller de permutación con flujo regular (flowshop) y compuesto de dos máquinas $M_{1}$ y $M_{2}$ y un almacén intermedio $B_{2}$ de capacidad igual a 1 trabajo. En este taller se desea secuenciar cuatro trabajos con los tiempos de proceso $\mathrm{p}_{\mathrm{i}, \mathrm{j}}, \mathrm{i}=1, . ., 4 \mathrm{y}$ $\mathrm{j}=1,2$ que se presentan en la Tabla 1 .

\begin{tabular}{ccc}
\hline $\mathbf{i}$ & $\mathbf{p}_{\mathbf{i}, 1}$ & $\mathbf{p}_{\mathbf{i}, 2}$ \\
\hline 1 & 2 & 11 \\
\hline 2 & 3 & \\
\hline 3 & 4 & 4 \\
\hline 4 & 11 & \\
\hline
\end{tabular}

flowshop con $\mathrm{N}=4$ y $\mathrm{M}=2$ 
En la Figura 2 representamos el diagrama de Gantt de la secuencia obtenida mediante la aplicación del algoritmo de
Jonhson es 1-2-3-4 y podemos observar que el makespan es 26.

Figura 2 Representación de un problema de secuenciación con almacenes intermedios según la secuencia obtenida mediante el algoritmo de Johnson. En línea de trazos se muestran las esperas de los trabajos en el almacén $B_{2}$

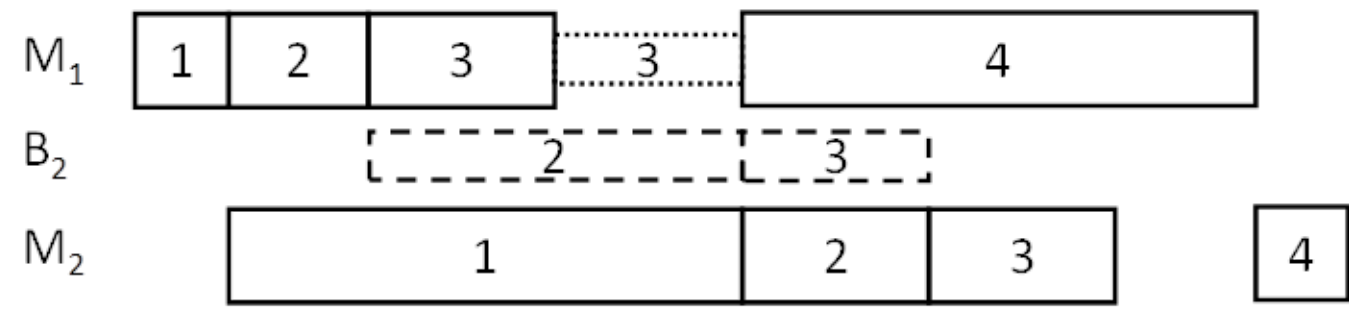

Según se desprende de la figura 2, podemos observar que el trabajo 2, tras finalizar su operación en la máquina $\mathrm{M}_{1}$, tiene que esperar durante 8 unidades de tiempo en el almacén $B_{2}$ de capacidad 1 hasta que el primer trabajo de la secuencia finaliza. Esto provoca que el trabajo 3, bloquee la máquina $M_{1}$, puesto que no puede ser enviado al almacén intermedio en el momento que finaliza debido a que está ocupado por el trabajo 2 hasta el instante 13. Del mismo modo, el trabajo 3, una vez que ha podido ser enviado al almacén intermedio, debe esperar en el mismo hasta que la máquina $\mathrm{M}_{2}$ acaba su operación sobre el trabajo 2 en el instante 17.

Una de las consecuencias más interesantes que produce la consideración de limitación de capacidad entre máquinas es que el problema a resolver cambia de una manera drástica. En efecto, en el ejemplo anterior, la secuencia 1-4-3-2 que se muestra en la Figura 3 produce una solución con un makespan igual a 25 y por lo tanto mejor que la que ofrece el algoritmo de Johnson que es sabido que garantiza optimalidad en el caso de secuenciación sin limitaciones de capacidad.

Figura 3 Representación de una solución mejorada del problema anterior.

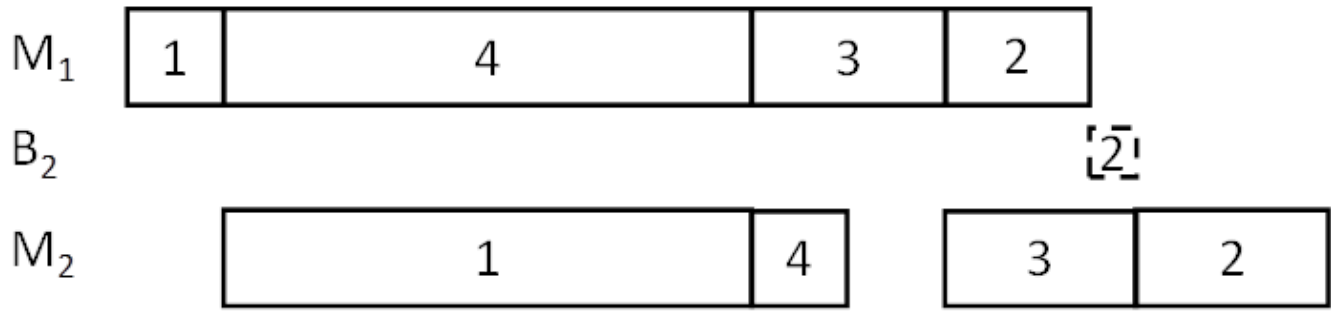

En el ejemplo anterior, se ve claramente el efecto de la limitación de capacidad en los problemas de secuenciación: para una secuencia concreta y debido a los efectos de bloqueo en las máquinas, que supone la saturación en determinados instantes de los almacenes intermedios, la temporización se ve afectada puesto que las fechas de inicio de los trabajos en un problema con capacidad limitada siempre serán iguales o mayores que las que se obtienen cuando consideramos capacidad infinita entre máquinas.

Otro aspecto a destacar sobre el ejemplo anterior es que en los almacenes intermedios no es necesario aplicar una disciplina FIFO para determinar el orden en el que los trabajos pasan a la siguiente máquina, sino que puede existir una secuencia de llegada al almacén y una secuencia (que puede ser diferente) de extracción de los trabajos del almacén. En general, y de forma similar al problema a capacidad infinita, la asunción de igualdad en la secuencia de entrada y salida del almacén se usa en las configuraciones flowshop, como plantea Leisten (1990), Smutnicki(1998) o Nowicki (1999), mientras que en los problemas que modelan configuraciones de flujo general se suele distinguir entre los dos tipos de secuencias puesto que no tienen que ser idénticas.
En la tesis doctoral de Heitmann (2007) se establece una clasificación de los tipos de almacenes intermedios para los problemas de secuenciación. Así, se distingue en primer lugar entre almacenes dependientes de los trabajos y dependientes de las máquinas. Los primeros son aquellos en los que la asignación al almacén depende del trabajo (por ejemplo, todas las veces que un determinado trabajo finaliza su procesado en una máquina, se envía al mismo almacén), mientras que, en el segundo caso, los trabajos son enviados a un almacén en función de la máquina que los ha procesado y en la que van a ser procesados a continuación. En este último caso, la misma autora distingue tres posibilidades: que la asignación al almacén solamente dependa de la máquina donde se realiza la operación previa (output buffer), que dependa de la máquina donde se realiza la operación siguiente (input buffer) o que dependa de ambas (pairwise buffer). Los dos primeros casos se usan en los modelos de secuenciación en configuraciones donde los trabajos siguen rutas diferentes (jobshop) mientras que el último se plantea en los modelos de secuenciación en configuraciones flowshop. En el ejemplo de la figura 2 , el almacén $B_{2}$ se considera un almacén del tipo pairwise. 
El citado trabajo de Leisten (1990) aborda también la relación existente entre cuatro tipos de problemas de secuenciación: los problemas sin restricción de capacidad, los problemas con capacidad limitada a un valor mayor que cero (limited/finite intermediate storage scheduling problem), los problemas con capacidad nula (blocking scheduling) y los problemas de secuenciación sin esperas (no-wait scheduling problem).
Los problemas de secuenciación con bloqueo aparecen cuando se considera que no existe capacidad de almacenamiento entre las máquinas. Debido a esto, si un trabajo acaba su operación en una máquina, solamente puede pasar a la máquina siguiente si esta se encuentra libre. En caso contrario, bloquea a la máquina en la que acaba de ser procesado hasta que pueda empezar la siguiente operación. En la Figura 4, podemos observar la secuencia planteada en la Figura 2 bajo las condiciones de bloqueo.

Figura 4 Representación de la secuencia obtenida mediante el algoritmo de

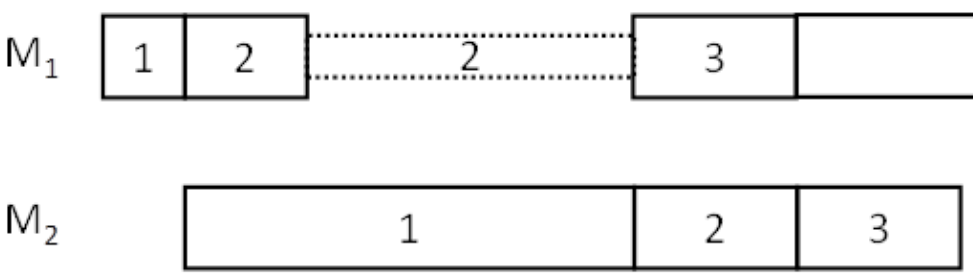
4 Johnson en un problema de secuenciación con bloqueo.

En cambio, en los problemas de secuenciación sin esperas se impone una restricción adicional a cada trabajo, que consiste en ajustar los instantes de inicio de las operaciones en las máquinas de tal forma que la fecha de fin coincida con la fecha de inicio de la siguiente operación, de tal manera que para cada trabajo no pueden existir esperas en ninguna de las operaciones que recibe. Esto se puede observar en la Figura 5.

Figura 5 Representación de la secuencia obtenida mediante el algoritmo de Johnson en un problema de secuenci-

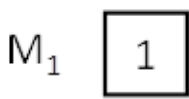

\begin{tabular}{|l|l|l|}
\hline 2 & 3 & 4 \\
\hline
\end{tabular}
ación sin esperas.

$\mathrm{M}_{2}$

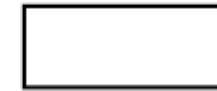

\section{1}

3

Como se puede ver si se comparan la Figura 4 y la Figura 5, la diferencia fundamental en ambos problemas es que, en el primer caso, las máquinas pierden capacidad de procesar nuevos trabajos puesto que no pueden procesar nada al estar bloqueadas. En cambio, en el problema sin esperas, pese a aparecer el mismo intervalo de inactividad en $\mathrm{M}_{1}$, esta podría procesar un trabajo de hasta ocho unidades de tiempo en ese intervalo de inactividad (en este caso, no afectaría al resto de los trabajos de la secuencia si el nuevo trabajo no necesitase ser procesado en $\mathrm{M}_{2}$.

En posteriores secciones de este artículo se revisarán las principales aportaciones para todas estas configuraciones y se observará que, en muchos casos, existen trabajos que tratan de resolver de la misma manera varias de las variantes citadas.

Por último, mencionar los sistemas de control de producción que, aunque no asumen explícitamente una limitación de la capacidad en los almacenes, sí que tratan de racionalizar la cantidad de inventario en curso dentro del flujo productivo. Dentro de este apartado se deben destacar las diferentes versiones del sistema KANBAN definido por vez primera en Sugimori et al. (1977), el CONWIP (Constant Work In Progress) de Spearman et al. (1989) y, en general, todos los sistemas basado en el uso de tarjetas o señales como DBR
(Drum Buffer and Rope) de Goldratt y Cox (1984), el sistema POLCA (Paired-cell Overlapping Loops of Cards with Authorization) de Suri (1998), el sistema COBACABANA (COntrol of BAlance by CArd-BAsed NAvigation) de Land (2009) entre otros. En todos estos casos, la limitación de capacidad deja de considerarse una restricción para convertirse en el objetivo de minimizar la cantidad de inventario en curso que está presente durante todo el horizonte de programación. En este artículo, no se considerarán este tipo de sistemas, sino que se remite al lector a las revisiones realizadas por Framinan et al. (2003), González et al. (2012) y Jaegler et al. (2017).

\section{Una revisión de la literatura}

A continuación, se procede a repasar las aportaciones encontradas sobre la secuenciación con capacidad limitada. Se han dividido en cuatro grandes apartados en función de las configuraciones productivas en las que se desarrollan los trabajos: taller de flujo con almacenes limitados (flowshop with limited buffers), talleres de flujo con restricciones de bloqueo o sin esperas (blocking/no-wait flowshops), taller general (jobshops) y otras configuraciones diferentes en donde el número de referencias es menor. 


\subsection{Flowshop con almacenes intermedios de capacidad limitada}

El primer trabajo del que se tiene constancia en la literatura sobre la problemática de secuenciación con limitaciones de capacidad es el artículo de Dutta y Cunningham (1975), donde se estudia una configuración flowshop con dos máquinas y se desarrolla un procedimiento de programación dinámica para resolverlo. Posteriormente, Papadimitriou y Kanellakis (1980) demostraron que el problema con buffer de capacidad limitada era NP-Completo, iniciando el creciente interés en el desarrollo de procedimientos de secuenciación en talleres flowshop que incorporan esta limitación. En el mismo artículo, los últimos autores plantearon la primera heurística específica para resolver este tipo de problemas y justificaron su rendimiento en función del tamaño del buffer para el caso de dos máquinas. De este modo, identificaron que la relación entre la fecha de fin del último trabajo (Cmax) con un buffer de capacidad b entre las dos máquinas y el mismo problema sin buffer es de $(b+1) /(2 b+1)$ donde b es el número de trabajos que puede contener el almacén de manera simultánea. En Knopf (1985) se aborda el problema de manera exacta en un flowshop de dos máquinas y en el contexto de secuenciación en industrias químicas, mediante un procedimiento de ramificación y acotación.

Sin embargo, no fue hasta el artículo ya citado de Leinsten (1990) en donde se plantea un modelo general para incorporar a los problemas de secuenciación las restricciones de capacidad. En este trabajo, se formaliza por primera vez la relación existente entre las fechas de inicio y de fin de los trabajos en las diferentes máquinas del flowshop en función de la capacidad de los almacenes intermedios. Esta formalización fue depurada por los citados trabajos de Smutnicki (1998) y Nowicki (1999). Para poder explicar mejor dicha formalización es necesario una serie de definiciones.

En primer lugar, puesto que se aborda el taller de flujo en el que solo se consideran secuencias basadas en permutaciones de los trabajos, se obviará el subíndice h de la operación. Por lo tanto, el tiempo de procesamiento del trabajo en cada una de las m máquinas se va a denotar por $\mathrm{p}_{\mathrm{ij}}>0$. Además, se consideran las asunciones básicas en este tipo de problemas, como son que los trabajos no se pueden interrumpir, que cada máquina procesa solo un trabajo a la vez o que cada trabajo solo puede estar siendo procesado en una máquina a la vez.

Entre cada par de máquinas j-1 y j existe un buffer o almacén Bj con capacidad b(j) dentro del cual se sigue una disciplina FIFO (esto implica que puede haber a la vez hasta b(j) trabajos entre las máquinas j-1 y j). Cada trabajo debe pasar por el almacén Bj cuando acaba en la máquina j-1 y ha de pasar a la máquina j. Como se ha planteado en la Figura 2 , si un trabajo acaba en la máquina j-1, solamente puede pasar a la máquina j si el almacén Bj no está completo. En caso que lo esté, el trabajo debe permanecer en la máquina (máquina bloqueada) hasta que se libere un espacio en el almacén y pueda pasar a él. Una máquina bloqueada impide la realización del siguiente trabajo en la misma hasta que el trabajo que la bloquea no pase al siguiente almacén. Para usar el índice i como identificador de la posición en la secuencia, se usará como representación del ordenamiento de los trabajos los valores $\pi_{[\mathrm{i}]}$ que permiten definir al trabajo que ocupa la posición i de la permutación. De esta manera, se definen los instantes de inicio de los trabajos que ocupan la posición $\pi_{[\mathrm{i}]}$ en la máquina j como $\mathrm{S}_{\pi[\mathrm{i}] \mathrm{j}^{j}}$. A partir de estos valores, se pueden identificar los instantes en los que los trabajos que ocupan cada posición finalizan su procesado en la máquina correspondiente y que se definen como $\mathrm{C}_{\pi[\mathrm{i}] \mathrm{j} j}=\mathrm{S}_{\pi[\mathrm{i}] \mathrm{j}}+\mathrm{p}_{\pi[\mathrm{i}] \mathrm{j} ;}$.

Sin embargo, como se observa en las figuras 3 y siguientes, este valor no tiene por qué coincidir con el instante en que cada trabajo pasa al almacén siguiente o a la máquina siguiente puesto que, debido a las limitaciones de bloqueo que imponen los almacenes intermedios, los trabajos pueden permanecer en las máquinas (bloqueándolas) más allá del instante en el que han terminado.

Así, a partir de una permutación concreta, se pueden establecer una serie de relaciones entre las fechas de inicio de los trabajos, sus fechas de fin y las fechas en las que cada trabajo puede abandonar la máquina. Por ejemplo, la ecuación [1] muestra la relación entre la fecha de inicio de un trabajo en una máquina y la fecha de inicio del mismo trabajo en la máquina que realiza la operación precedente es:

$S_{\pi[i] j} \geq S_{\pi[i] j-1}+p_{\pi[i] j-1}=C_{\pi[i] j-1}$

Esto es, la fecha de inicio del trabajo que ocupa la posición i en la máquina j debe ser mayor o igual que la fecha de inicio del trabajo que ocupa la posición i en la máquina anterior más el tiempo de proceso del trabajo en la máquina anterior (que a su vez es la fecha en la que el trabajo i acaba en la máquina anterior). Nowicki (1999), a partir de la formalización del problema mediante un grafo, denomina a este tipo de relaciones de tipo V o Verticales. Por otro lado, también, como se observa en la ecuación [2] se debe cumplir que la fecha de inicio del trabajo que ocupa la posición i en la máquina j debe ser mayor o igual que la fecha de inicio del trabajo que ocupa la posición anterior en esa misma máquina más el tiempo de proceso del trabajo anterior en la máquina. Esto a su vez es la fecha en la que el trabajo anterior acaba en la máquina.

$$
S_{\pi[i] j} \geq S_{\pi[i-1] j}+p_{\pi[i-1] j}=C_{\pi[i-1] j}
$$

Este tipo de relaciones se denominan de tipo $\mathrm{H} \mathrm{u}$ Horizontales. Estos dos tipos de relaciones son las típicas del flowshop de permutación y se pueden sintetizar en la ecuación [3]:

$$
S_{\pi[i] j}=\operatorname{Max}\left\{S_{\pi[i-1] j}+p_{\pi[i-1] j} ; S_{\pi[i] j-1}+p_{\pi[i] j-1}\right\}
$$


Sin embargo, cuando existen limitaciones de capacidad por los almacenes intermedios aparece una nueva relación que prohíbe que un trabajo pueda empezar en una máquina si no ha salido del almacén que hay a continuación de la máquina el trabajo que ocupa en la secuencia una posición anterior que depende de la capacidad del almacén. Esta relación se expresa en la ecuación [4]:

$S_{\pi[i] j} \geq S_{\pi[i-b(j+1)-1] j+1}$

Así, un trabajo no puede empezar en una máquina si no ha empezado en la siguiente el trabajo que va en la posición $b(j+1)-1$. Nowicki (1999) denomina a este tipo de relaciones de tipo D o Diagonales.

Las relaciones anteriores nos permiten calcular el valor de $\mathrm{S}_{[\mathrm{ijj}}=\max \left(\mathrm{C}_{[\mathrm{i}] \mathrm{j}-1}, \mathrm{C}_{[\mathrm{i}-1 \mathrm{1}] \mathrm{j}}, \mathrm{S}_{[\mathrm{i}-\mathrm{b}(\mathrm{j}+1) \mathrm{f}-1] \mathrm{j}+1}\right)$ de una manera general $\mathrm{y}$, de esta manera, el problema se reduce a calcular la secuencia de la permutación $\pi$ que minimiza $\operatorname{Cmax}(\pi)=\mathrm{S}_{\pi(\mathrm{N}) \mathrm{M}}{ }^{+} \mathrm{p}_{\pi(\mathrm{N}) \mathrm{M}}$. Donde $\mathrm{S}_{[\mathrm{N}] \mathrm{M}}=\max \left(\mathrm{S}_{[\mathrm{N}] \mathrm{M}-1}, \mathrm{C}_{[\mathrm{N}-1] \mathrm{M}}\right)$

Para poder representar los tiempos de permanencia en los almacenes o los tiempos de bloqueo, en Pinedo (2010), se define $\mathrm{D}_{\text {[ilj }}$ como la fecha en la que el trabajo [i] finalmente abandona la máquina j. En el caso de secuenciación sin limitación de capacidad $\mathrm{C}_{[\mathrm{i}] \mathrm{j}}=\mathrm{D}_{[\mathrm{i}] \mathrm{j}}$ mientras que en el caso de limitación de capacidad, este valor puede coincidir o ser superior a $\mathrm{C}_{\text {[ilj }}$ ya que el trabajo puede quedar bloqueado en la máquina debido a la saturación del buffer posterior, aunque haya terminado. La expresión que permite calcular $\mathrm{D}_{[\mathrm{ijj}}$ a partir de $\mathrm{S}_{[\mathrm{i}] \mathrm{j}}$ se expresa mediante la ecuación [5]:

$D_{[i] j}=\max \left(C_{[i] j]}, S_{[i-b(j+1)] j+1}\right)$

A partir de las expresiones anteriores, se pueden establecer las fórmulas que permiten calcular las fechas de inicio de los trabajos en un taller de flujo con almacenes intermedios. Estas relaciones se sintetizan en las ecuaciones [6] a [13]

$S_{\pi[1] j}=0 \quad i=1 ; j=1$

$S_{\pi[1] j}=S_{\pi[i] j-1}+p_{\pi[i] j-1} \quad j=2, \ldots, M$

$S_{\pi[i] 1}=S_{\pi[i-1] 1}+p_{\pi[i-1] 1} i=2, \ldots, b_{j+1}+1$

$S_{\pi[i] 1}=\operatorname{Max}\left\{S_{\pi[i-1] 1}+p_{\pi[i-1] 1} ; S_{\pi\left[i-b_{j+1}-1\right]_{2}}\right\} i>b_{j+1}+1$

$S_{\pi[i] j}=\operatorname{Max}\left\{S_{\pi[i-1] j}+p_{\pi[i-1] j} ; S_{\pi[i] j-1}+p_{\pi[i] j-1}\right\} i=2, \ldots, b_{j+1}+1 ; j=2, \ldots, M-1$

$S_{\pi[i] j}=\operatorname{Max}\left\{S_{\pi[i-1] j}+p_{\pi[i-1] j} ; S_{\pi[i] j-1}+p_{\pi[i] j-1} ; S_{\pi\left[i-b_{j+1}-1\right] j+1}\right\}$

$i>b_{j+1}+1 ; j=2, \ldots, M-1$

$S_{\pi[i] j}=\operatorname{Max}\left\{S_{\pi[i-1] j}+p_{\pi[i-1] j} ; S_{\pi[i] j-1}+p_{\pi[i] j-1}\right\} i=2, \ldots, N ; j=M$

$C \max =S_{\pi[N] M}+p_{\pi[N] M}$
En el artículo de Leisten (1990) se realiza un estudio en el que se comparan once reglas heurísticas, entre ellas una regla basada en el trabajo de Papadimitriou y Kanellakis (1980) o la regla NEH de Nawaz et al. (1989), además de heurísticas propias aplicadas en orden directo y también en orden inverso de las máquinas. La conclusión del estudio es que la regla $\mathrm{NEH}$ es la mejor de todas las heurísticas planteadas.

En los trabajos de Smutnicki (1998) y Nowicki (1999) se plantea el uso de un grafo dirigido para representar este problema. En este caso, todos los nodos (j,i) (máquina, trabajo) representan el instante de inicio del trabajo que está en la posición $\pi_{[i]}$ en la máquina j y tienen un peso igual al tiempo de proceso $\mathrm{p}_{[\mathrm{i}] \mathrm{j}}$. Todos los arcos tienen valor cero excepto los arcos que representan las relaciones debidas al buffer que tienen un valor debido al tiempo de proceso negativo $\mathrm{p}_{[\mathrm{i}-\mathrm{b}(\mathrm{j}+1)-1] \mathrm{j}+1}$. A partir de este modelado basado en grafos, se desarrolla un procedimiento rápido para calcular el makespan de una secuencia determinada y, finamente, se desarrolla un algoritmo de Búsqueda Tabú que aprovecha las propiedades anteriores para determinar vecindarios eficientes.

En el artículo de Brucker et al. (2003) se amplía el modelo anterior para el caso de flowshop general en el que no se impone la condición de que la permutación sea la misma en todas las máquinas. De una forma similar al trabajo de Nowicki (1999), los autores definen una serie de movimientos que usan dentro de un algoritmo de búsqueda tabú.

Wang et al. (2006) abordan el mismo problema de secuenciación flowshop de permutación, pero esta vez mediante un Algoritmo Genético y estudian el efecto del tamaño de los almacenes sobre el makespan. Otros trabajos en los que se usan metaheurísticas en este problema son los de Norman (1999) quien resuelve el problema mediante Búsqueda Tabú y considera tiempos de preparación dependientes de la secuencia, el trabajo de Liu et al. (2008) en el que usan Particle Swarm Optimization, el algoritmo inmunitario de Hsieh et al. (2009), el algoritmo de evolución diferencial de Qian et al. (2009), el algoritmo caótico de búsqueda armónica de Pan et al. (2011a), el algoritmo basado en evolución diferencial de Pan et al. (2011b), el algoritmo basado en colonias de hormigas de Rossi y Lanzetta (2013) aplicado a talleres de flujo generales o el algoritmo basado en sistemas inmunológicos artificiales de Abdollahpour y Rezaeian (2015).

Desmarcándose de toda la literatura anterior en la que se considera que la capacidad limitada en los almacenes se expresa en función del número de trabajos que pueden almacenarse a la vez, Witt y Voss (2007) consideran la posibilidad de que cada trabajo ocupe una cantidad de espacio diferente y desarrollan tres heurísticas para abordar este tipo de situaciones. 
Por último, mencionar los trabajos relacionados con la secuenciación de lotes con solapamiento (lot streaming) entre máquinas consecutivas. Andreatta et al. (1995) plantean un sistema de fabricación flexible tipo flowshop de dos máquinas con dos almacenes intermedios entre las máquinas. El primer almacén es la salida de la primera máquina que a su vez abastece al segundo almacén que es la entrada a la segunda máquina. Los lotes de piezas del primer almacén no se transfieren al segundo hasta que este no se vacía. Siguiendo esta idea, el trabajo de Agnetis et al. (1997) demuestra una serie de propiedades para el caso de dos máquinas con un almacén intermedio de capacidad limitada.

En la Tabla 1 se muestran ordenadas alfabéticamente todas las referencias citadas sobre el problema flowshop, indicando el procedimiento (o procedimientos) de resolución y las observaciones sobre el trabajo si fuera necesario (en general, en todos los trabajos, la función objetivo a minimizar es Cmax):
Tabla 1 Referencias sobre el problema flowshop

\begin{tabular}{|c|c|c|}
\hline Referencia & Procedimientos de resolución & Observaciones \\
\hline Dutta y Cunningham (1975) & PD & $\mathrm{M}=2$ \\
\hline Papadimitriou y Kanellakis (1980) & Heurística & Demostración NP-Hard \\
\hline Knopf (1985) & $B \& B$ & M=2/Industria química \\
\hline Leisten (1990) & Heurísticas & $\begin{array}{l}\text { Relación entre problemas sin esperas, } \\
\text { con bloqueo o capacidad limitada }\end{array}$ \\
\hline Andreatta et al., (1995) & Heurística & $\begin{array}{c}\text { Flowshop de dos máquinas con lot } \\
\text { streaming }\end{array}$ \\
\hline Agnetis et al. (1997) & Heurísticas & $\begin{array}{l}\text { Propiedades de las secuencias en flow- } \\
\text { shop de dos máquinas con lot streaming. }\end{array}$ \\
\hline Smutnicki (1998) & BT & Grafos \\
\hline Nowicki (1999) & BT & \\
\hline Norman (1999) & BT & Tiempos de preparación \\
\hline Brucker et al., (2003) & BT & No permutación \\
\hline Wang et al., (2006) & $\mathrm{AG}+\mathrm{BL}$ & Estudio del tamaño de los almacenes \\
\hline Witt y Voss (2007) & Heurísticas & Trabajos de tamaño diferente \\
\hline Liu et al., (2008) & ОСР & \\
\hline Hsieh et al., (2009), & AIS & \\
\hline Qian et al, (2009) & $\mathrm{DE}$ & \\
\hline Pan et al. (2011a) & ABCA & \\
\hline Pan et al. (2011b) & ED & \\
\hline Rossi y Lanzetta, (2013) & $\mathrm{OCH}$ & No permutación \\
\hline Abdollahpour y Rezaeian (2015) & SAI & \\
\hline
\end{tabular}

PD: programación dinámica, BL: búsqueda local, B\&B: ramificación y acotación, BT: búsqueda tabú, AG: algoritmo genético, OCP: optimización por cúmulos de partículas, OCH: optimización mediante colonias de hormigas, SAI: sistema artificial inmune, ED: Evolución diferencial, ABCA: algoritmo de búsqueda caótica armónica 


\subsection{Flowshop con bloqueo y sin esperas}

Como ya se ha comentado en la sección 2, si en la configuración de taller de flujo simple (flowshop) se supone que el tamaño de almacén es igual a cero, nos encontramos con los denominados flowshop con bloqueo (blocking). Según se indica en Pinedo (2010), esta aproximación permite representar un buffer de la máquina y con capacidad bj sin más que reemplazarlo por bj máquinas con bloqueo y tiempo de proceso nulo previas a la máquina j.

Existe una variante aún más restrictiva de los flowshops con bloqueo denominada configuración flowshop sin esperas (no-wait) en donde los trabajos no pueden esperar ni entre las máquinas ni en las máquinas. El primer artículo conocido que aborda alguna de estas variantes es el de Levner (1969), quien planteó la manera de calcular el makespan de este problema en función del camino más crítico en un grafo. Los trabajos realizados desde esta fecha hasta la primera mitad de los años 90 se pueden encontrar en el artículo de Hall y Sriskandarajah (1996) donde se hace un extensivo repaso de las referencias existentes de problemas con bloqueo y nowait hasta esa fecha. Desde entonces, no se ha hecho ningún trabajo que revise la literatura más reciente en los problemas de secuenciación en flowshop con bloqueo pese a que han sido bastante numerosos. Así, se pueden destacar los trabajos de Ronconi y Armentano (2001) quienes plantean un algoritmo Branch and Bound para resolver estos problemas. En un artículo posterior, Ronconi (2004) define una heurística sencilla denominada MM para resolverlo y demuestra su superioridad frente a la heurística NEH de Nawaz et al. (1983). Finalmente, Ronconi (2005) plantea un nuevo algoritmo Branch and Bound que mejora su algoritmo exacto propuesto anteriormente. Con el objetivo de ser aplicable a diversos entornos, Liu y Kozan (2009a) desarrollan una heurística para abordar problemas de secuenciación con bloqueo, sin esperas, con capacidad finita o infinita. A partir de un caso multiobjetivo inspirado en una empresa siderúrgica, Gong et al. (2010) plantean un modelo en de flowshop donde existe bloqueo en la primera máquina y tiempos de preparación en la segunda. En los trabajos de Bautista et al. (2011) y Bautista et al. (2012) se desarrollan varios procedimientos de resolución basados en programación dinámica acotada para el problema de flowshop de permutación con bloqueo lográndose mejoras en varias de las instancias de Taillard (1993).

Un interesante artículo de McCormick et al. (1989) aborda una configuración tipo flowshop con almacenes intermedios y en contexto de fabricación cíclica, aunque centran su estudio en la variante con bloqueo para lo que presentan una regla denominada Profile Fitting (PF) con el objetivo de minimizar el tiempo de ciclo. En esta línea aparece el trabajo de Abadi et al. (2000), en el que presentan una aproximación a este mismo problema basada en aumentar los tiempos de proceso de las operaciones bloqueadas y transformar el problema en un problema no-wait, usando entonces las heurística GENIUS desarrollada por Gendreau y Laporte (1992) que ofrece resultados casi óptimos para este tipo de problemas.
También se han realizado trabajos en los que se utilizan diversas metaheurísticas para resolver el problema de secuenciación con bloqueo. Entre ellos cabe destacar el algoritmo genético de Caraffa et al. (2001) o las dos variantes de búsqueda tabú de Grabowski y Pempera (2007). Más recientemente, Wang et al. (2010a) han usado un algoritmo basado en evolución diferencial discreta y Companys et al. (2010) han desarrollado una heurística constructiva aleatorizada para resolver este mismo problema. En Ribas et al. (2011) se desarrolla un algoritmo Iterated Greedy que parte de soluciones iniciales obtenidas mediante una mejora de la heurística NEH y en Liang et al. (2011) se plantea un algoritmo basado en múltiples cúmulos de partículas mientras que Wang et al. (2011) proponen un algoritmo basado en búsqueda armónica. Pan y Wang (2012) realizan un estudio donde demuestran que la heurística PF combinada con la NEH es muy efectiva en este tipo de problemas. Sin embargo, todos los resultados anteriores son mejorados por Ribas y Companys (2013) usando una metaheurística VNS en combinación con propiedades basadas en la reversibilidad del problema. Mosheli y Khorasanian (2014) presenta un algoritmo basado también en búsquedas por entornos variables pero no lo comparan con el trabajo de Ribas y Companys(2013). Recientemente, Eddaly et al. (2016) abordan el problema mediante un algoritmo basado en cúmulo de partículas, aunque el algoritmo más competitivo hasta la fecha es el procedimiento greedy iterativo propuesto por Tasgetiren et al. (2017) el cual mejora los resultados anteriores.

Recientemente, han aparecido una serie de artículos que centran su interés en la minimización del tiempo promedio de flujo en el sistema de configuraciones flowshop con bloqueo. Por ejemplo, Wang et al. (2010b), Deng et al. (2012), Khorasanian y Moslehi (2012) o Lin y Ying (2013) abordan este problema mediante metaheurísticas, mientras que Moslehi y Khorasanian (2013) plantean un procedimiento de ramificación y acotación que es válido para instancias reducidas del problema. Ribas y Companys (2015) estudian el comportamiento de dos reglas constructivas y cuatro variantes de un algoritmo GRASP en un amplio conjunto de instancias, igualando las mejores soluciones conocidas en instancias pequeñas y mejorando las soluciones en las instancias de tamaño grande. Recientemente, Tasgetiren et al. (2016) aborda la optimización de tiempo de flujo total mediante el uso de heurísticas de inserción de bloques variables y también consiguen mejorar algunos de los resultados existentes en instancias grandes de la literatura. Fernandez-Viagas et al. (2016) presentan una heurística "Beam search" que consigue también resultados superiores a varias heurísticas previas.

En cuanto a otras medidas de eficiencia, solamente se ha encontrado el trabajo de Ronconi y Enriques (2009) donde minimizan la tardanza total en un sistema flowshop con bloqueo mediante una serie de heurísticas y un algoritmo GRASP que ofrecen resultados competitivos respecto a los obtenidos por la heurística NEH. 
En el caso de configuraciones flowshop sin esperas, Allahverdi (2016) ha publicado una nueva revisión de toda la literatura existente desde 1993 hasta la actualidad que abarca unos 300 artículos y que muestra el interés de la comunidad científica por este tipo de problemas.
En la Tabla 2 se muestran ordenadas alfabéticamente todas las referencias citadas sobre el problema flowshop sin esperas o con bloqueo. Indicando el procedimiento (o procedimientos) de resolución y, en observaciones, la función objetivo o características adicionales consideradas:
Tabla 2 Referencias sobre el problema flowshop sin esperas o con bloqueo.

\begin{tabular}{|c|c|c|}
\hline Referencia & Procedimientos de resolución & Observaciones \\
\hline Levner (1969) & Grafos & Cmax \\
\hline McCormick et al. (1989) & Heurística & Sistemas cíclicos con bloqueo \\
\hline Hall y Sriskandarajah (1996) & & Estado del arte hasta 1996 \\
\hline Abadi et al. (2000) & GENIUS & Sistemas cíclicos con bloqueo \\
\hline Ronconi y Armentano (2001) & $\mathrm{B} \& \mathrm{~B}$ & Cmax, Bloqueo \\
\hline Ronconi (2004) & Heurística & Cmax, Bloqueo \\
\hline Ronconi (2005) & $\mathrm{B} \& \mathrm{~B}$ & Cmax, Bloqueo \\
\hline Liu y Kozan (2009a) & Heurística & $\begin{array}{l}\text { Cmax, problemas con bloqueo, sin } \\
\text { esperas, con y sin capacidad limit- } \\
\text { ada }\end{array}$ \\
\hline Caraffa et al. (2001) & AG & Cmax, Bloqueo \\
\hline Grabowski y Pempera (2007) & BT & Cmax \\
\hline Ronconi y Enriques (2009) & Heurísticas, GRASP & $\sum_{\mathrm{Li}}$ \\
\hline Wang et al. (2010a) & Evolución diferencial & Cmax \\
\hline Wang et al. (2010b) & Búsqueda híbrida armónica & $\sum_{\mathrm{Ci}}$ \\
\hline Gong et al. (2010) & PD & Cmax/tiempo de bloqueo \\
\hline Companys et al. (2010) & BLI & Cmax \\
\hline Bautista et al. (2011) & PDA & Cmax \\
\hline Ribas et al. (2011) & IG & Cmax \\
\hline Liang et al. (2011) & MPSO & Cmax \\
\hline Wang et al. (2011) & Algoritmo de búsqueda armónica & Cmax \\
\hline Bautista et al. (2012) & PDA & Cmax \\
\hline Deng et al. (2012) & $\mathrm{BC}$ & $\sum \mathrm{Ci}$ \\
\hline Khorasanian y Moslehi (2012) & BIV & $\sum \mathrm{Ci}$ \\
\hline Pan y Wang (2012) & Heurística & Cmax \\
\hline
\end{tabular}




\begin{tabular}{ccc}
\hline Lin y Ying (2013) & SAI & Con bloqueo \\
\hline Moslehi y Khorasanian (2013) & B\&B & Ci \\
\hline Ribas y Companys (2013) & BEV & Cmax \\
\hline Moslehi y Khorasanian (2014) & IG & Cmax \\
\hline Ribas y Companys (2015) & Heurísticas, GRASP \\
\hline Eddaly et al. (2016) & OCP & Cmax \\
\hline Tasgetiren et al. (2016) & Heurística & $\sum$ Ci \\
\hline Fernandez-Viagas et al. (2016) & BH & Ci \\
\hline Allahverdi (2016) & & Estado del arte sobre flowshop sin \\
\hline
\end{tabular}

PDA: programación dinámica acotada, PD: programación dinámica, B\&B: ramificación y acotación, BT: búsqueda tabú, AG: algoritmo genético, BLI: búsqueda local iterativa, BIV: búsqueda iterativa voraz, ACA: algoritmo basado en colonias de abejas, OCP: optimización por cúmulos de partículas, SAI: sistema artificial inmune, BEV: búsqueda por entorno variable, BH: búsqueda basada en haces, BIV: búsqueda iterativa voraz

\subsection{Jobshop con almacenes intermedios de capacidad limitada o nula}

El primer trabajo relacionado con configuraciones jobshop fue el de Luh et al. (1998) quienes analizaron una planta de fabricación de interruptores de Toshiba. En este caso, también consideraron tiempos de preparación dependientes de familias de productos, abordando el problema mediante una combinación de relajación lagrangiana, programación dinámica y heurísticas.

En Brucker et al. (2006) y en la, ya citada, tesis doctoral de Heitmann (2007) se estudió de manera general el problema a partir de representaciones de las diferentes modalidades de buffer ya citadas en la sección 2. Estas representaciones se basan en grafos disyuntivos ya utilizados por Mascis y Pacciarelli (2002) para problemas jobhop con bloqueo y sin esperas y permitirían, según sus autores, desarrollar cotas o procedimientos rápidos de acotación dentro de estrategias más amplias de búsqueda local o ramificación y acotación.

Witt y Voss (2010) extendieron su trabajo previo (ya citado en la sección 3.1.) para abordar la problemática en jobshop desarrollando una heurística para determinar soluciones factibles en este contexto.
En el caso de secuenciación con bloqueo, se han de destacar los artículos de Brizuela et al. (2001), el trabajo ya citado de Mascis y Pacciarelli (2002), Brucker y Kampmeyer (2008), el de Liu y Kozan (2009b) en el contexto de secuenciación de ferrocarriles o el de Gröflin y Klinkert (2009) quienes abordan el problema añadiendo también operaciones de transferencia entre máquinas y tiempos de preparación y desarrollan un algoritmo de búsqueda tabú a partir del modelado del problema mediante grafos disyuntivos. Más recientemente, Pranzo y Pacciarelli (2015) resuelven este problema utilizando la metaheurística Iterated Greedy con resultados que superan todos los trabajos anteriores y Liu y Kozan (2016) estudian el caso de configuraciones jobshop con más de una máquina capaz de hacer cada operación, modelándolo mediante programación matemática y resolviéndolo mediante una metaheurística que hibridiza búsqueda tabú y recocido simulado. Finalmente, Khoranasian y Mosheli (2017) estudian el caso de una configuración flowshop de dos máquinas con bloqueo, flexibilidad en la primera máquina y posibilidad de interrumpir los trabajos.

En la Tabla 3 se muestran ordenadas alfabéticamente todas las referencias citadas sobre el problema jobshop, indicando el procedimiento (o procedimientos) de resolución y alguna observación especial sobre el trabajo: 
Tabla 3 Referencias sobre el problema jobshop.

\begin{tabular}{|c|c|c|}
\hline Referencia & Procedimientos de resolución & Observaciones \\
\hline Luh et al. (1998) & $\begin{array}{l}\text { Programación dinámica, relajación la- } \\
\text { grangiana y heurísticas }\end{array}$ & $\begin{array}{l}\text { Capacidad limitada en empresa fabri- } \\
\text { cación interruptores }\end{array}$ \\
\hline Brizuela et al. (2001) & AG & Con bloqueo y sin esperas \\
\hline Mascis y Pacciarelli (2002) & Grafos & Con bloqueo y sin esperas \\
\hline Brucker et al. (2006) & Grafos & Capacidad limitada \\
\hline Brucker y Kampmeyer (2008) & BT & Con bloqueo y sin esperas \\
\hline Heitmann (2007) & Grafos & Capacidad limitada \\
\hline Liu y Kozan (2009b) & Heurística & $\begin{array}{l}\text { Con bloqueo y sin esperas en un caso de } \\
\text { secuenciación de ferrocarriles }\end{array}$ \\
\hline Gröflin y Klinkert (2009) & BT & $\begin{array}{l}\text { Con tiempos de preparación, operaciones } \\
\text { de transferencia, bloqueo y sin esperas }\end{array}$ \\
\hline Witt y Voss (2010) & Heurística & $\begin{array}{l}\text { Capacidad limitada y trabajos de tamaño } \\
\text { diferente }\end{array}$ \\
\hline Pranzo y Pacciarelli (2015) & BIV & Con bloqueo y sin esperas \\
\hline Liu y Kozan (2016) & $\mathrm{BT}+\mathrm{RS}$ & $\begin{array}{c}\text { Múltiples máquinas por operación, con } \\
\text { bloqueo y sin esperas }\end{array}$ \\
\hline Khoranasian y Mosheli (2017) & BEV & $\begin{array}{c}\text { Con bloqueo, posibilidad de interrumpir } \\
\text { los trabajos y flexibilidad }\end{array}$ \\
\hline
\end{tabular}

RS: recocido simulado, BT: búsqueda tabú, AG: algoritmo genético, BIV: búsqueda iterativa voraz, BEV: búsqueda por entorno variableBIV: búsqueda iterativa voraz

\subsection{Otras configuraciones con almacenes inter- medios de capacidad limitada}

En este último apartado se recogen otros trabajos que se han hecho relacionados con configuraciones diferentes a las anteriores. El caso más sencillo sería el de considerar solamente una máquina con un almacén limitado a la entrada o a la salida. Así, Bolat (1997), aborda una configuración con una máquina en tiempo real con almacenes limitados a la entrada y propone una heurística para encontrar buenas soluciones en tiempo polinomial. También es interesante la serie de artículos de Hall et al. (1997), Hall et al. (1998a) y Hall et al. (1998b) en donde se tratan diferentes casos de secuenciación en una máquina con almacenes limitados a la entrada y a la salida, mostrando que en algunos casos se pueden resolver de manera eficiente.

En el contexto de flowshop híbrido (flowshop con más de una máquina por operación) se puede citar como pionero el artículo de Wittrock (1988) en el que presenta un algoritmo constructivo para resolver el problema con el objetivo de min- imizar el makespan y el inventario en curso. Posteriormente, Khosla (1995) aborda un problema en dos etapas inspirado en un caso de fabricación de circuitos impresos. En la primera etapa existen varias máquinas en paralelo que abastecen a una máquina de la etapa segunda y, entre ambas, existe un único almacén común de capacidad limitada. En este caso, se formula un modelo matemático basado en la consideración de que los almacenes se reemplazan por máquinas con bloqueo de capacidad nula y se estudia el problema mediante reglas de prioridad sencillas. En el trabajo de Belaid et al. (2012) se generaliza este contexto a un caso real en una empresa de cosmética en el que existen tiempos de preparación y varios almacenes posibles para cada tipo de trabajo y que es resuelto mediante varias heurísticas y una metaheurística basada en Colonias de Hormigas.

Para el flowshop híbrido generalizado hay que citar el modelo exacto de Sawik (2000), quien plantea la posibilidad de que un trabajo pueda ser procesado varias veces en alguna etapa, la heurística de Thornton y Hunsucker (2004) para un flowshop híbrido sin almacenes intermedios o los algoritmos basados en Búqueda Tabú de Wardono y Fathi (2004) y el 
de Wang y Tang (2009). Tang y Xuan (2006) plantean un método de resolución del problema basado en la relajación lagrangiana de un modelo de programación matemática en el que se consideran los almacenes de capacidad bj como bj máquinas de tiempo de procesamiento nulo. En el trabajo de Yaurima et al. (2009) se aborda mediante algoritmos genéticos el caso de una empresa de fabricación de televisores modelada como un flowshop híbrido, con almacenes y tiempos de setup. Li y Pan (2015) resuelven este problema mediante un algoritmo que combina búsqueda tabú con métodos basados en enjambres de abejas.

Maleki et al. (2012) abordan una configuración flowshop con ensamblaje de tres etapas en la que se fabrican los m componentes de cada trabajo en una primera etapa formada por m máquinas en paralelo, luego se transportan mediante la segunda etapa y, finalmente se ensamblan. Este problema se plantea con bloqueo y tiempos de preparación dependientes de la secuencia y se resuelve mediante recocido simulado.

Recientemente, Ribas et al. (2017) han abordado el problema en configuraciones denominadas flowshops en paralelo y sistemas flowshop distribuidos con bloqueo donde plantean diversas heurísticas constructivas y un algoritmo de búsqueda por entorno variable que se demuestra efectivo para instancias grandes de este tipo de problemas.
Sawik (2002) amplía su formulación matemática, ya citada, de talleres de flujo híbridos para incorporar el procesado de lotes con solapamiento. En el artículo de Pranzo (2004) se plantea una variante del anterior al que se añaden tiempos de preparación independientes de la secuencia y que se resuelve mediante una aproximación a un problema de viajante de comercio (en inglés travelling salesman problema o TSP).

La única referencia encontrada sobre un estudio de un taller de flujo híbrido no determinista y capacidad limitada en el sector siderúrgico es la de Almeder y Hartl (2013) quienes plantean una metaheurística basada en VNS que posteriormente es evaluada mediante un modelo de simulación.

En la Tabla 4 se muestran ordenadas alfabéticamente todas las referencias citadas en este apartado, indicando el procedimiento (o procedimientos) de resolución y alguna observación especial sobre el trabajo:
Tabla 4 Referencias sobre otras configuraciones.

\begin{tabular}{|c|c|c|}
\hline Referencia & Procedimientos de resolución & Observaciones \\
\hline Wittrock (1988) & Heurística & Flowshop híbrido \\
\hline Khosla (1995) & Heurística & $\begin{array}{c}\text { Flowshop híbrido de dos etapas en em- } \\
\text { presa de fabricación electrónica }\end{array}$ \\
\hline Bolat (1997) & Heurística & Una máquina \\
\hline Hall et al. (1997) & Heurística & Una máquina \\
\hline Hall et al. (1998a) & Heurística & Una máquina \\
\hline Hall et al. (1998b) & Heurística & Una máquina \\
\hline Sawik (2000) & Modelo matemático & $\begin{array}{l}\text { Flowshop híbrido de n etapas con reen- } \\
\text { trada }\end{array}$ \\
\hline Sawik (2002) & Modelo matemático & $\begin{array}{l}\text { Flowshop híbrido de n etapas con solap- } \\
\text { amiento }\end{array}$ \\
\hline Pranzo (2004) & Aproximación al TSP. Heurística & $\begin{array}{c}\text { Flowshop híbrido de n etapas con solapa- } \\
\text { miento y tiempos de preparación }\end{array}$ \\
\hline Thornton y Hunsucker (2004) & Heurística & Flowshop híbrido sin almacenes \\
\hline Wardono y Fathi (2004) & BT & Flowshop híbrido \\
\hline Tang y Xuan (2006) & Relajación lagrangiana & Flowshop híbrido \\
\hline Yaurima et al. (2009) & AG & $\begin{array}{l}\text { Flowshop híbrido en empresa de fabri- } \\
\text { cación de televisores }\end{array}$ \\
\hline Wang y Tang (2009) & BT & Flowshop híbrido \\
\hline
\end{tabular}




\begin{tabular}{ccc}
\hline Maleki et al. (2012) & RS & $\begin{array}{c}\text { Assemly Flowshop de tres etapas con } \\
\text { bloqueo y tiempos de preparación }\end{array}$ \\
\hline Belaid et al., (2012) & Heurísticas/OCH & $\begin{array}{c}\text { Flowshop híbrido de dos etapas con } \\
\text { tiempos de preparación y almacenes de- } \\
\text { pendientes de los trabajos }\end{array}$ \\
\hline Almeder y Hartl (2013) & BEV/Simulación & Tiempos no deterministas \\
\hline Li y Pan (2015) & ACA/BT & \\
\hline Ribas et al. (2017) & Heurísticas/BEV & Flowshops paralelos/distribuidos \\
\hline
\end{tabular}

RS: recocido simulado, BT: búsqueda tabú, AG: algoritmo genético, BIV: búsqueda iterativa voraz, BEV: búsqueda por entorno variable, OCH: optimización mediante colonias de hormigas, ACA: algoritmo basado en colonias de abejas

\section{Conclusiones}

La consideración de la capacidad limitada en los problemas de secuenciación cambia drásticamente las características de los mismos, haciendo que, incluso los casos resolubles óptimamente mediante algoritmos polinomiales, dejen de serlo. Además, presenta una gran importancia desde el punto de vista práctico porque permiten incorporar restricciones que acercan los modelos a la problemática real. Pese a que se han desarrollado una importante cantidad de trabajos en los últimos 20 años, consideramos que aún es un campo en el que los investigadores interesados en la programación de operaciones y la secuenciación pueden realizar importantes aportaciones.

Según se ha visto en la revisión mostrada, casi la totalidad de los trabajos realizados asumen que todos los trabajos representan la misma capacidad de almacenamiento. Sin embargo, en la realidad no es así y creemos que es necesario desarrollar más modelos analíticos y procedimientos de resolución que consideren esta casuística.

También se ha observado que la mayoría de los trabajos se centran en el makespan como medida a optimizar. Sin embargo, otras medidas más relacionadas con el inventario en curso, como es el tiempo de flujo total, solo se han analizado en el contexto de secuenciación con bloqueo y/o sin esperas. Solo hay una referencia que aborde otro tipo de medidas relacionadas con las fechas de entrega. Por ello, pensamos que es interesante el estudio de estas otras medidas diferentes de Cmax en este tipo de configuraciones (incluyendo las denominadas medidas de eficiencia no regulares que son aquellas que no empeoran necesariamente con el aumento de las fechas de finalización de cada trabajo).

Existen configuraciones que deben ser estudiadas con más profundidad debido a su importancia de cara a modelar procesos productivo-logísticos. En concreto, sistemas de talleres distribuidos que exijan una sincronización entre las etapas en entornos de fabricación ajustada, configuraciones con posibilidad de fraccionar los lotes, sistemas mixtos con ensamblajes, etc.
Finalmente, creemos que es necesario profundizar en el estudio de problemas que incorporen restricciones relacionadas con el modelo de almacenamiento como pueden ser los tiempos de carga y descarga, los transportes, la necesidad de recursos adicionales, etc... de tal manera que se incluyan en los problemas de secuenciación restricciones que permitan añadir aspectos más realistas a los problemas de secuenciación con capacidad limitada.

\section{Reconocimiento}

In memoriam al profesor Reiner Leisten por su aportación al área de secuenciación de operaciones y por sus trabajos pioneros en el contexto de secuenciación con capacidad limitada.

\section{Referencias}

ABADI, I. N. K., HALL, N. y SRISKANDARAJAH, C. (2000). «Minimizing Cycle Time in a Blocking Flowshop». Operations Research. 48, 177-180

ABDOLLAHPOUR, S. y REZAEIAN, J. (2015). «Minimizing makespan for flow shop scheduling problem with intermediate buffers by using hybrid approach of artificial immune system». Applied Soft Computing. 28, 44-56.

AGNETIS, A., PACCIARELLI, D. y ROSSI, F. (1997). «Batch scheduling in a two-machine flow shop with limited buffer». Discrete Applied Mathematics. 72, 243260.

ALMEDER, C. Y HARTL, R. F. (2010). «A metaheuristic optimization approach for a real-world stochastic flexible flow shop problem with limited buffer». International Journal of Production Economics. 145, (1), 88-95

ALLAHVERDI, A. (2016). «A survey of scheduling problems with no-wait in process». European Journal of Operational Research. 255 (3), 665-686. 
BAUTISTA, J., CANO, A., COMPANYS, R. y RIBAS, I. (2011). «A Bounded Dynamic Programming algorithm for the Blocking Flow Shop problem». IEEE Workshop On Computational Intelligence In Production And Logistics Systems (CIPLS 2011).

BAUTISTA, J., CANO, A., COMPANYS, R. y RIBAS, I. (2012). «Solving the Fm block Cmax problem using Bounded Dynamic Programming». Engineering Applications of Artificial Intelligence. 25(6), 1235-1246.

BELAÏD, R., T’KINDT, V. y ESSWEIN, C. (2012). «Scheduling batches in flowshop with limited buffers in the shampoo industry». European Journal of Operational Research. 223, 560-572.

BOLAT, A. (1997). «Sequencing jobs for an automated manufacturing module with buffer». European Journal of Operational Research. 96, 622-635

BRIZUELA, C.A., ZHAO, Y. y SANNOMIYA, N. (2001). «No-wait and blocking job-shops: Challenging problems for GA's». 2001 IEEE International Conference on Systems, Man and Cybernetics. 2349-2354.

BRUCKER, P., HEITMANN, S. y HURINK, J. (2003). «Flow-shop problems with intermediate, buffers». OR Spectrum. 25, 549-574

BRUCKER, P., HEITMANN, S., HURINK,J. y NIEBERG, T., (2006). «Job-shop scheduling with limited capacity buffers». OR Spectrum 28, 151-176

BRUCKER, P. y KAMPMEYER, T. (2008). «Cyclic job shop scheduling problems with blocking». Annals of Operations Research, 159 (2008), 161-181

CARAFFA, V., IANES, S.P., BAGCHI, T. y SRISKANDARAJAH, C. (2001). «Minimizing makespan in a blocking flowshop using genetic algorithms». International Journal of Production Economics. 70 (2), 101-115.

COMPANYS, R. y COROMINAS, A. (1996). «Organización de la Producción II. Dirección de Operaciones 4». Barcelona. Ed. UPC

COMPANYS, R., RIBAS, I. y MATEO, M. (2010). «Note on the behaviour of an improvement heuristic on permutation and blocking flowshop scheduling». International Journal of Manufacturing Technology and Management. 20, 331-357

DENG, G., XU, Z., y GU, X. (2012). «A discrete artificial bee colony algorithm for minimizing the total flow time in the blocking flow shop scheduling». Chinese Journal of Chemical Engineering, 20(6), 1067-1073
DUTTA, S.K. y CUNNINGHAM, A.A. (1975). «Sequencing two-machine flow-shops with finite intermediate storage ». Management Science, 21(9), 989-996

EDDALI, M., JARBOUI, B. Y SIARRY., P. (2016). «Combinatorial particle swarm optimization for solving blocking flowshop scheduling problem». Journal of Computational Design and Engineering, 3(4), 295-311

FERNANDEZ- VIAGAS, V. LEISTEN, R. y FRAMINAN, J. M. (2016). «A computational evaluation of constructive and improvement heuristics for the blocking flow shop to minimise total flowtime». Expert Systems with Applications. 61(1), 290-301

FRAMINAN, J. M., GONZALEZ, P. L., y RUIZ-USANO, R. (2003). «The Conwip production control system: Review and research issues». Production Planning \& Control, 14(3), 255-265.

GENDREAU, M., HERTZ, A. y LAPORTE, G. (1992). «New insertions and postoptimization Procedures for the Travelling Salesman Problem», Operations Research.40, 1086-1094.

GOLDRATT, E. M. y COX, J. (1984). «The Goal: An ongoing improvement process». New York: North River Press.

GONG, H., TANG, L. y DUIN, C.W. (2010). «A two-stage flow shop scheduling problem on a batching machine and a discrete machine with blocking and shared setup times». Computers \& Operations Research. 37(5), 960969

GONZALEZ, P. L., FRAMINAN, J. M. y PIERREVAL, H. (2012). «Token-based pull production control systems: an introductory overvie». Journal of Intelligent Manufacturing. 23, 5-22.

GRABOWSKI, J. y PEMPERA, J. (2007) «The permutation flow shop problem with blocking. A tabu

search approach». Omega. 35(3), 302-311.

GRÖFLIN, H. y KLINKERT, A. (2009). «A new neighborhood and tabu search for the Blocking Job Shop». Discrete Applied Mathematics. 157(17), 3643-3655

HALL, N.G., POSNER, M.E. y POTTS, C. N. (1997). «Preemptive scheduling with finite capacity input buffers». Annals of Operations Research. 70, 399-413.

HALL, N.G., POSNER, M.E. y POTTS, C. N. (1998a). «Scheduling with finite capacity input buffers». Operations Research. 46, 154-159. 
HALL, N.G., POSNER, M.E. y POTTS, C. N. (1998b). «Scheduling with finite capacity output buffers». Operations Research. 46, 84-97.

HEITMANN, S. (2007). «Job-shop scheduling with limited buffer capacities». Tesis Doctoral. Universidad de Osnabrück.

HSIEH, Y., YOU, P. y LIOU, C. (2009). «A note of using effective immune based approach for the flow shop scheduling with buffers». Applied Mathematics and Computation. 215, pp. 1984-1989.

JAEGLER, Y., JAEGLER, A., BURLAT, P., LAMOURI, S. y TRENTESAUX, D. (2017). " The ConWip production control system: a systematic review and classification». International Journal of Production Research (en prensa), DOI: 10.1080/00207543.2017.1380325

JOHNSON, S. M. (1954). «Optimal two and three stage production schedules with set-up time included». Naval Research Logistics Quaterly, 1, 161-168

KHORASANIAN, D. y MOSLEHI, G., (2012). «An iterated greedy algorithm for solving the blocking flow shop scheduling problem with total flow time criteria». International Journal of Industrial Engineering \& Production Research, 23 (4), 301-308

KHORASANIAN, D. y MOSLEHI, G. (2017). «Two-machine flow shop scheduling problem with blocking, multi-task flexibility of the first machine, and preemption». Computers \& Operations Research. 79, 94-108

KNOPF, F. C. (1985). «Sequencing a generalized two-stage flowshop with finite intermediate storage». Computers \& Chemical Engineering. 9(3), 207-221.

KHOSLA, I. (1995). «The scheduling problem where multiple machines compete for a common local buffer». European Journal of Operational Research. 84, 330-342

LAND, M. J. (2009). «Cobacabana (control of balance by card-based navigation): A card-based system for job shop control». International Journal of Production Economics, 117(1), 97-103.

LEINSTEN, R. (1990). «Flowshop sequencing problems with limited buffer storage». International Journal of Production Research. 28, 2085-2100.

LEVNER, E. M. (1969). «Optimal planning of parts machining on a number of machines». Automation and Remote Control. 12, 1972-1978.
LI, J. y PAN, Q. (2015). «Solving the large-scale hybrid flow shop scheduling problem with limited buffers by a hybrid artificial bee colony algorithm». Information Sciences. 316(20), 487-502.

LIANG, J.J., PAN, Q., TIEJUN, C. y WANG, L. (2011). «Solving the blocking flow shop scheduling problem by a dynamic multi-swarm particle swarm optimizer». International Journal of Advanced Manufacturing Technology, 55(5-8), 755-762.

LIN, S. y YING, K. (2013). « Minimizing makespan in a blocking flowshop using a revised artificial immune system algorithm». Omega. 41(2), 383-389.

LIU, B., WANG, L. y JIN, Y. (2008). «An effective hybrid PSO-based algorithm for flow shop scheduling with limited buffers». Computers \& Operations Research. 35, 2791-2806

LIU, S.Q. y KOZAN, E. (2009a). «Scheduling a flow shop with combined buffer conditions». International Journal of Production Economics. 117, 371-380,

LIU, S.Q. y KOZAN, E. (2009b). «Scheduling trains as a blocking parallel-machine job shop scheduling problem», Computers and Operations Research. 36, 28402852

LIU, S.Q. y KOZAN, E. (2016). «Parallel-identical-machine job-shop scheduling with different stage-dependent buffering requirements». Computers \& Operations Research. 74, 31-41.

LUH, P.B., GOU, L., ZHANG, Y., NAGAHORA, T., TSUJI, M., YONEDA, K., HASEGAWA, T., KYOYA, Y. y KANO, T. (1998). «Job shop scheduling with group-dependent setups, finite buffers, and long time horizon». Annals of Operations Research. 76, 233-259.

MALEKI-DAROUNKOLAEI, A., MODIRI, M., TAVAKKOLI-MOGHADDAM, R. y SEYYEDI, I. (2012). «A three-stage assembly flow shop scheduling problem with blocking and sequence-dependent set up times». Journal of Industrial Engineering International. 8, 26

MASCIS, A. y PACCIARELLI, D., (2002). «Job-shop scheduling with blocking and no-wait, constraints». European Journal of Operational Research, 143, 498- 517

MCCORMICK, S.T., PINEDO, M. I., SHENKER, S. y WOLF, B., (1989). "Sequencing in an assembly line with blocking to minimize cycle time». Operations Research. 37, 925-936 
MOSLEHI, G., y KHORASANIAN, D. (2013). «Optimizing blocking flow shop scheduling problem with total completion time criterion». Computers \& Operations Research,40(7), 1874-1883

MOSLEHI, G., y KHORASANIAN, D. (2014). « A hybrid variable neighborhood search algorithm for solving the limited-buffer permutation flow shop scheduling problem with the makespan criterion». Computers \& Operations Research,52(B), 260-268.

NAWAZ, M., ENSCORE, E. E. y HAM, I., (1983). «A heuristic algorithm for the m-machine, $n$-job flowshop sequencing problem». Omega 11(1),91-95

NORMAN, B. A. (1999). «Scheduling flowshops with finite buffers and sequence- dependent setup times». Computers \& Industrial Engineering. 36, 163-177

NOWICKI, E. (1999). «The permutation flow shop with buffers: a tabu search approach». European Journal of Operational Research, 116, 205-219.

PAN, Q.K., WANG, L. y GAO, L. (2011). «A chaotic harmony search algorithm for the flow shop scheduling problema with limited buffers». Applied Soft Computing. 11, 5270-5280

PAN, Q.K. y WANG, L. (2012). «Effective heuristics for the blocking flowshop scheduling problem with makespan minimization». Omega, 40, 218-229

PAPADIMITRIOU, C. H. y KANELLAKIS, P.C. (1978). «Flowshop scheduling with limited temporary storage». Journal of ACM. 27, 533-549.

PINEDO, M. (2010). «Scheduling. Theory, algorithms and systems». Ed Springer. New York

PRANZO, M. (2004). «Batch scheduling in a two-machine flow shop with limited buffer and sequence independent setup times and removal times». European Journal of Operational Research. 153, 581-592

PRANZO, M. y PACCIARELLI, D. (2015). «An iterated greedy metaheuristic for the blocking job shop scheduling problem». Journal of Heuristics. 22(4), 587-611.

QIAN , B., WANG, L., HUANG, D.X. y WANG, X. (2009). «An effective hybrid DE-based algorithm for flow shop scheduling with limited buffers». International Journal of Production Research, 47(1), 1-24.

RIBAS, I., COMPANYS, R. y TORT-MARTORELL, X. (2011). «An iterated greedy algorithm for the flowshop scheduling problem with blocking». Omega 39, 293301.
RIBAS, I. y COMPANYS, R. (2013). «A competitive variable neighbourhood search algorithm for the blocking flow shop problem». European Journal of Industrial Engineering. 7(6), 729-753

RIBAS, I. y COMPANYS, R. (2015). «Efficient heuristic algorithms for the blocking flow shop scheduling problem with total flow time minimization». Computers and Industrial Engineering. 87, 30-39

RIBAS, I., COMPANYS, R. y TORT-MARTORELL, X. (2017). «Efficient heuristics for the parallel blocking flow shop scheduling problem». Expert Systems with Applications. 74(15), 41-54

RONCONI, D. y ARMENTANO, V. (2001). «Lower boundings schemes for flowshops with blocking in process». Journal of the Operational Research Society. 52, 12891297

RONCONI, D. (2004). «A note on constructive heuristics for the flowshop problem with blocking». International Journal of Production Economics, 39-48

RONCONI, D. (2005). «A branch-and-bound algorithm to minimize the makespan in a flowshop with blocking». Annals of Operations Research, 53-65

RONCONI, D. P. y ENRIQUES, L.R.S. (2009). «Some heuristic algorithms for total tardiness minimization in a flowshop with blocking». 37(2), 272-281

ROSSI, A. y LANZETTA, M. (2013). «Scheduling flow lines with buffers by ant colony digraph». Expert Systems with Applications. 40, 3328-3340

SAWIK, T. (2000). «Mixed Integer Programming for Scheduling Flexible Flow Lines with Limited Intermediate Buffers». Mathematical and Computer Modelling. 31, 39-52

SAWIK, T. (2002). «An Exact Approach for Batch Scheduling in Flexible Flow Lines with Limited Intermediate Buffers». Mathematical and Computer Modelling. 36, 461-471

SMUTNICKI, C. (1998). «A two-machine permutation flow shop scheduling problem with buffers». OR Spektrum. 20, 229-235

SPEARMAN, M. L., HOPP, W. J. H., y WOODRUFF, D. L. (1989). "A hierarchical control architecture for Constant Work-in-Process (CONWIP) production systems». Journal of Manufacturing Operation and Management, 2, 147-171. 
SUGIMORI, Y., KUSUNOKI, K., CHOR, F. y UCHIKAWA, S. (1977). «Toyota production system and Kanban system Materialization of just-in-time and respect for-human system». International Journal of Production Research, 15(6), 553-564.

SURI, R. (1998). «Quick response manufacturing: A company-wide approach to lead time reduction». Portland, OR: Productivity Press.

TAILLARD, E. (1993). «Benchmarks for basic scheduling problems», European Journal of Operational Research, 64(2), 278-285.

TANG, L. y XUAN, H. (2006). «Lagrangian relaxation algorithms for real-time hybrid flowshop scheduling with finite intermediate buffers». Journal of the Operational Research Society, 57, 316-24.

TASGETIREN, M. F., PAN, Q., KIZILAY, D. y GAO, K. (2016). «A Variable Block Insertion Heuristic for the Blocking Flowshop Scheduling Problem with Total Flowtime Criterion». Algorithms, 9, 71.

TASGETIREN, M. F., KIZILAY, D., PAN, Q., y SUGANTHAN, P. N. (2017). «Iterated greedy algorithms for the blocking flowshop scheduling problem with makespan criterion». Computers and Operational Research, 77, 111-126.

THORNTON, H.W. Y HUNSUCKER, J.L. (2004). «A new heuristic for minimal makespan in flow shops with multiple processors and no intermediate storage». European Journal of Operational Research. 152(1), 96-114.

WANG, L. ZHANG, L. y ZHENG, D., (2006). «An effective hybrid genetic algorithm for flow shop scheduling with limited buffers». Computers \& Operations Research. 33, 2960-2971

WANG, X. y TANG, L. (2009). «A tabu search heuristic for the hybrid flowshop scheduling with finite intermediate buffers». Computers \& Operations Research. 36, 907918
WANG, L., PAN, Q., SUGANTHAN,P.N., WANG, W. y WANG, Y. (2010a). «A novel hybrid discrete differential evolution algorithm for blocking flow shop scheduling problems», Computers \& Operations Research, 37(3), 509-520.

WANG, L., PAN, Q., y TASGETIREN, M. (2010b). «Minimizing the total flow time in a flow shop with blocking by using hybrid harmony search algorithms». Expert Systems with Applications, 37(12), 7929-7936

WANG, L., PAN, Q., y TASGETIREN, M. (2011). « A hybrid harmony search algorithm for the blocking permutation flow shop scheduling problem». Computers \& Industrial Engineering, 61(1), 76-83

WARDONO B. y FATHI, Y. (2004) «A tabu search algorithm for the multi-stage parallel machine problems with limited buffer capacities». European Journal of Operational Research. 155, 380-401.

WITT, A., y VOSS, S., (2007). «Simple heuristics for scheduling with limited intermediate storage». Computers \& Operations Research 34, 2293-2309

WITT, A., y VOSS, S., (2010). «Job Shop scheduling with buffer constraints and Jobs consuming variable buffer space». Advanced manufacturing and susteinable logistics. Proceedings del 8th International Heinz Nixdorf Symposium, IHNS 2010, Ed. Springer. Germany

WITTROCK, R. J. (1988). «An adaptable scheduling algorithm for flexible flow lines». Operations Research. 36, 445-453

YAURIMA, V., BURTSEVA, L. y TCHERNYKH, A. (2009). «Hybrid flowshop with unrelated machines, sequence-dependent setup time, availability constraints and limited buffers». Computers \& Industrial Engineering. 56, 1452-1463. 